\title{
Therapeutic window for melanoma treatment provided by selective effects of the proteasome on Bcl-2 proteins
}

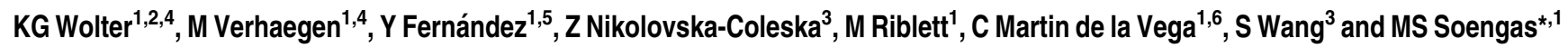

Melanoma cells depend on sustained proteasomal function for survival. However, bortezomib, the first proteasome inhibitor in clinical use, is not sufficient to improve the poor prognosis of metastatic melanoma patients. Since the proteasome is also expressed in all normal cell compartments, it is unclear how to enhance the efficacy of bortezomib without exacerbating secondary toxicities. Here, we present pharmacological and genetic analyses of mechanisms of resistance to proteasome inhibition. We focused on $\mathrm{Bcl}-2, \mathrm{Bcl}-\mathrm{x}_{\mathrm{L}}$ and $\mathrm{Mcl}-1$ as main antiapoptotic factors associated with melanoma progression. Despite an efficient blockage of the proteasome, bortezomib could not counteract the intrinsically high levels of Bcl-2 and Bcl- $\mathrm{x}_{\mathrm{L}}$ in melanoma cells. Moreover, Mcl-1 was only downregulated at late time points after treatment. Based on these results, a combination treatment including (-)-gossypol, an inhibitor of $\mathrm{Mcl}-1 / \mathrm{Bcl}-2 / \mathrm{Bcl}-\mathrm{x}_{\mathrm{L}}$, was designed and proven effective in vivo. Using a specific RNA interference approach, the survival of bortezomib-treated melanoma cells was found to rely primarily on $\mathrm{Mcl}-1$, and to a lesser extent on Bcl- $\mathrm{x}_{\mathrm{L}}$ (but not on Bcl-2). Importantly, neither Mcl-1 nor Bcl- $\mathrm{x}_{\mathrm{L}}$ inactivation affected the viability of normal melanocytes. This hierarchical requirement of $\mathrm{Bcl}-2$ family members for the maintenance of normal and malignant cells offers a therapeutic window to overcome melanoma chemoresistance in a tumor cell-selective manner.

Cell Death and Differentiation (2007) 14, 1605-1616; doi:10.1038/sj.cdd.4402163; published online 1 June 2007

Metastatic melanoma remains a daunting clinical problem. In addition to a continuous rise in incidence, the prognosis of patients at late stages of the disease has not significantly improved in the last three decades. ${ }^{1}$ However, recent discoveries elucidating aspects of the underlying molecular biology of metastatic melanoma have led to optimism about the rational design of more effective treatments. ${ }^{2,3}$ The proteasome may one such attractive new target for cancer therapeutics. In experimental models, melanoma cells are highly dependent on proteasomal function for survival. ${ }^{4-8}$ Thus, bortezomib, the prototype of selective proteasome inhibitors currently in clinical trials, ${ }^{9}$ can compromise the viability of a spectrum of melanoma cells derived from early, intermediate or late stages of the disease. ${ }^{6}$

Genetic and functional studies in melanoma and other cancers have identified the proapoptotic protein NOXA as an early target of bortezomib..$^{5-8,10,11}$ The specific contribution of NOXA to cell death may be context dependent, ${ }^{12}$ but a main role of this protein is to neutralize the antiapoptotic factor Mcl$1 .^{13,14}$ Intriguingly, while a 5- to 20 -fold accumulation of NOXA in melanoma cells can be visualized as early as $6 \mathrm{~h}$ posttreatment with bortezomib, caspase activation may not be detected until $12-48 \mathrm{~h}_{\text {later. }}{ }^{6}$ Therefore, these cells seemingly retain antiapoptotic activities to counteract proteasome inhibition and NOXA upregulation. Understanding how normal and tumor cells activate survival pathways to compensate for proteasomal inhibition may be important in vivo. For example, although bortezomib can synergize with various chemotherapeutic agents, this proteasome inhibitor failed to reveal significant efficacy in a recent clinical trial with metastatic melanoma patients. ${ }^{15}$

The development of treatments tailored to enhance the efficacy of bortezomib without increasing its secondary toxicity has been complicated by a lack of consensus on the impact of proteasome inhibition on the apoptotic cascade in tumor cells. In particularly, the impact of bortezomib on $\mathrm{Bcl}-2$ family members is unclear. Depending on the cell type, Bcl-2, $\mathrm{Bcl}-\mathrm{x}_{\mathrm{L}}$ and Bax can be either unaffected by bortezomib, downregulated before the activation of the apoptotic machinery, or inhibited after caspases are processed. ${ }^{9,16} \mathrm{Mcl}-1$ levels accumulate in response to bortezomib, ${ }^{6-8}$ but $\mathrm{Mcl}-1$ is also cleaved by caspases once apoptosis is induced. .,17 Interestingly, partial downregulation of $\mathrm{Mcl}-1$ was shown to cause a twofold increase in bortezomib-mediated melanoma killing in culture. $^{7}$ The question of how to efficiently block Mcl-1 and improve the antitumoral activity of bortezomib in vivo remains.

\footnotetext{
${ }^{1}$ Department of Dermatology, University of Michigan, Comprehensive Cancer Center, Ann Arbor, MI, USA; ${ }^{2}$ Department of Surgery, University of Michigan, Comprehensive Cancer Center, Ann Arbor, MI, USA and ${ }^{3}$ Department of Internal Medicine, University of Michigan, Comprehensive Cancer Center, Ann Arbor, MI, USA *Corresponding author: MS Soengas, Department of Dermatology, University of Michigan, Comprehensive Cancer Center (4217 CCGC), 1500 E Medical Center Dr., Ann Arbor, MI 48109, USA. Tel: 734936 5643; Fax: 734647 9654; E-mail: soengas@umich.edu

${ }^{4}$ These authors contributed equally to this work.

${ }^{5}$ Current address: Merck KGaA, Bioresearch Laboratory, Parc Científic de Barcelona, Barcelona, Spain.

${ }^{6}$ Current address: Spanish National Cancer Research Centre (CNIO), Madrid, Spain.

Keywords: melanoma; chemoresistance; apoptosis; cancer therapy; tumor maintenance

Abbreviations: $\mathrm{BH} 3, \mathrm{Bcl}-2$ homology domain 3; Cyt $c$, cytochrome $c$; DAPI, 4',6-diamidino-2-phenylindole; FAM, 6-carboxyfluorescein succinimidyl ester; GFP, green fluorescent protein; i.v., intravenous; s.c., subcutaneous; shRNA, short hairpin RNA

Received 13.11.06; revised 02.4.07; accepted 03.4.07; Edited by JP Medema; published online 01.6.07
} 
Small molecule inhibitors of antiapoptotic $\mathrm{Bcl}-2$ proteins are emerging as potent tools to address functional components of the apoptotic machinery, with the ultimate objective of overcoming tumor chemoresistance. ${ }^{18,19}$ Intense effort has been dedicated to the development of compounds that mimic the $\mathrm{Bcl}-2$ homology domain $3(\mathrm{BH} 3)$ domain of pro-death $\mathrm{Bcl}-2$ proteins. ${ }^{18,20} \mathrm{ABT}-737$, the best characterized $\mathrm{BH} 3$ mimetic to date, synergizes with compounds such as dexamethasone or paclitaxel. ${ }^{21}$ Unfortunately, ABT-737 had a relatively modest effect on the cytotoxicity of bortezomib (1.3-fold induction of cell death). ${ }^{22}$ A likely explanation for this limited cooperation is that $A B T-737$ has a high affinity for $\mathrm{Bcl}-2$ and $\mathrm{Bcl}-\mathrm{x}_{\mathrm{L}}$, but binds poorly to $\mathrm{Mcl}-1,{ }^{21}$ which is induced by bortezomib. Broader spectrum antagonists of antiapoptotic $\mathrm{Bcl}-2$ proteins are being investigated (reviewed by Zhai et $\mathrm{al}^{20}{ }^{20}$ ). These include the natural products or derivatives of epigallocatechin gallate (EGCG), gossypol, antimycin A and chelerythrine; as well as synthetic compounds GX-15, BH3I-1, TW-37 and YC-137. Among these, the lowest $\mathrm{IC}_{50}$ values for $\mathrm{Mcl}-1$ have been reported for EGCG and gossypol (0.92 and $1.75 \mu \mathrm{M}$, respectively). Gossypol is interesting because, to our knowledge, it is the only bioavailable compound able to bind $\mathrm{Mcl}-1^{23}$ that is in being tested in phase II clinical trials. ${ }^{24}$ In the context of melanoma, gossypol has long been known to kill melanoma cells more efficaciously than normal melanocytes. ${ }^{25-27} \mathrm{How}$ ever, the mechanism(s) underlying this selectivity is unclear.

Here, we report a comparative analysis of cell survival mechanisms in melanoma cells and normal melanocytes with blocked proteasomal function. We combine genetic and pharmacological approaches (based on RNA interference and gossypol, respectively) to address the impact of specific Bcl-2 family members in response to bortezomib in vitro and in vivo. We show that the regulation and functional requirement of $\mathrm{Bcl}-2, \mathrm{Bcl}-\mathrm{x}_{\mathrm{L}}$ and $\mathrm{Mcl}-1$ are not equivalent in melanoma cells versus normal melanocytes. Moreover, melanoma cells, but not melanocytes, require $\mathrm{Mcl}-1$ and $\mathrm{Bcl}-\mathrm{x}_{\mathrm{L}}$ for survival when the proteasome is blocked. This study provides new insight into the relationship between the proteasome and the apoptotic machinery in melanoma, which could be exploited to design more effective and selective therapies.

\section{Results}

Identification of protective signals opposing bortezomib killing of melanoma cells. To address mechanisms of melanoma resistance to bortezomib, SK-Mel-19, SK-Mel-103 and SK-Mel-147 were chosen as representative melanoma cell lines that respond to bortezomib by undergoing programmed cell death. ${ }^{5,6}$ Consistent with previous reports, ${ }^{5,6}$ bortezomib induced NOXA efficiently in all three lines, but was not rapidly cytotoxic (Figure 1a-c). Cells were collected at different time points following bortezomib treatment, and the expression of NOXA, Mcl-1, Bcl- $\mathrm{x}_{\mathrm{L}}$ and $\mathrm{Bcl}-2$ visualized by immunoblotting. Processing of regulatory caspases (casp-9 and -8) and effector caspases (casp-3 and -7) was monitored as a classical indicator of apoptosis activation.

As shown in Figure $1 \mathrm{a}-\mathrm{c}$, in all analyzed melanoma cell lines, $\mathrm{Mcl}-1$ protein levels rapidly increased following bortezomib treatment. A 2- to 2.5-fold Mcl-1 induction was detectable within $1 \mathrm{~h}$ of incubation with bortezomib, preceding the accumulation of NOXA (see quantification of relative induction of the two proteins in Figure $1 \mathrm{a}-\mathrm{c}$; and the accumulation of NOXA and $\mathrm{Mcl}-1$ in Figure $1 \mathrm{~d}-\mathrm{f}$ ). Note that significant cell death was not achieved until regulatory and effector caspase cleavage was detected and Mcl-1 expression was reduced to or below basal levels (Figure $1 \mathrm{~d}-\mathrm{f}$ ). Bcl-2 and $\mathrm{BCl}-\mathrm{x}_{\mathrm{L}}$ expression remained high during treatment, and did not change upon caspase cleavage. These results emphasize the differential regulation of $\mathrm{Bcl}-2$ family members by the proteasome, supporting the notion that the idiosyncratic rate of synthesis and accumulation of $\mathrm{Mcl}-1$ may serve as an internal brake opposing the toxicity of proteasomal inhibition. $^{7}$

Multitarget $\mathrm{BH} 3$ mimetics to improve the efficacy of bortezomib. Given the massive induction of $\mathrm{Mcl}-1$ by bortezomib, and the sustained levels of $\mathrm{Bcl}-2$ and $\mathrm{Bcl}-\mathrm{x}_{\mathrm{L}}$, after treatment, blocking these three antiapoptotic proteins may improve the efficacy of proteasome inhibition in vivo. To test this possibility, we focused on gossypol, a bioavailable compound with $\mathrm{BH} 3$ functions, which had a safe profile in clinical trials. ${ }^{23}$

Natural gossypol (a mixture of $(-)$ and $(+)$ enantiomers) binds $\mathrm{Mcl}-1, \mathrm{Bcl}-2$ and $\mathrm{Bcl}-\mathrm{X}_{\mathrm{L}}$ with $\mathrm{IC}_{50}$ values of $1.74,0.28$ and $3.03 \mu \mathrm{M}$, respectively. ${ }^{20}$ However, a number of reports have shown that of the two enantiomers, (-)-gossypol is significantly the most potent anticancer agent in vitro and in vivo. $^{23}$ To estimate the binding affinities of $(-)$-gossypol for individual $\mathrm{Bcl}-2$ family members, competition fluorescence polarization assays were performed with a fluorescently tagged Bid $\mathrm{BH} 3$ peptide. ${ }^{24} K_{\mathrm{i}}$ values were determined instead of binding concentrations, as they more directly measure the inhibitory capacity of (-)-gossypol. As shown in Figure 2a, the $K_{\mathrm{i}}$ values of (-)-gossypol for $\mathrm{Mcl}-1, \mathrm{Bcl}-2$ and $\mathrm{Bcl}-\mathrm{X}_{\mathrm{L}}$ were 180 , 320 and $480 \mathrm{nM}$, respectively. Because of its high affinity for Mcl-1, we utilized the (-) enantiomer of gossypol in our studies of melanoma resistance to bortezomib.

When combined with bortezomib in vitro, (-)-gossypol selectively enhanced melanoma cell death. As shown in Figure $2 \mathrm{~b}$, the addition of (-)-gossypol increased cell killing in each of the melanoma lines tested, without affecting the viability of normal melanocytes (Figure 2b, see also Figure 2c for representative microphotographs). These data suggest a tumor-restricted cooperativity between (-)-gossypol and proteasome inhibition.

Antitumor effect of the (-)-gossypol/bortezomib combination in vivo. We have previously shown that, among a panel of 19 melanoma lines, the SK-Mel-103 and SK-Mel-147 lines grow most aggressively in immunosuppressed mice. ${ }^{6}$ Therefore, these two cell lines were selected for treatment assays in vivo.

To enable non-invasive tumor visualization, SK-Mel-103 and SK-Mel-147 cells were infected with retroviral vectors encoding green fluorescent protein (GFP). Melanoma cells were then implanted subcutaneously (s.c.) to generate localized xenografts, or intravenously (i.v.) to induce disseminated tumors. Treatment was initiated once tumor cells 
a
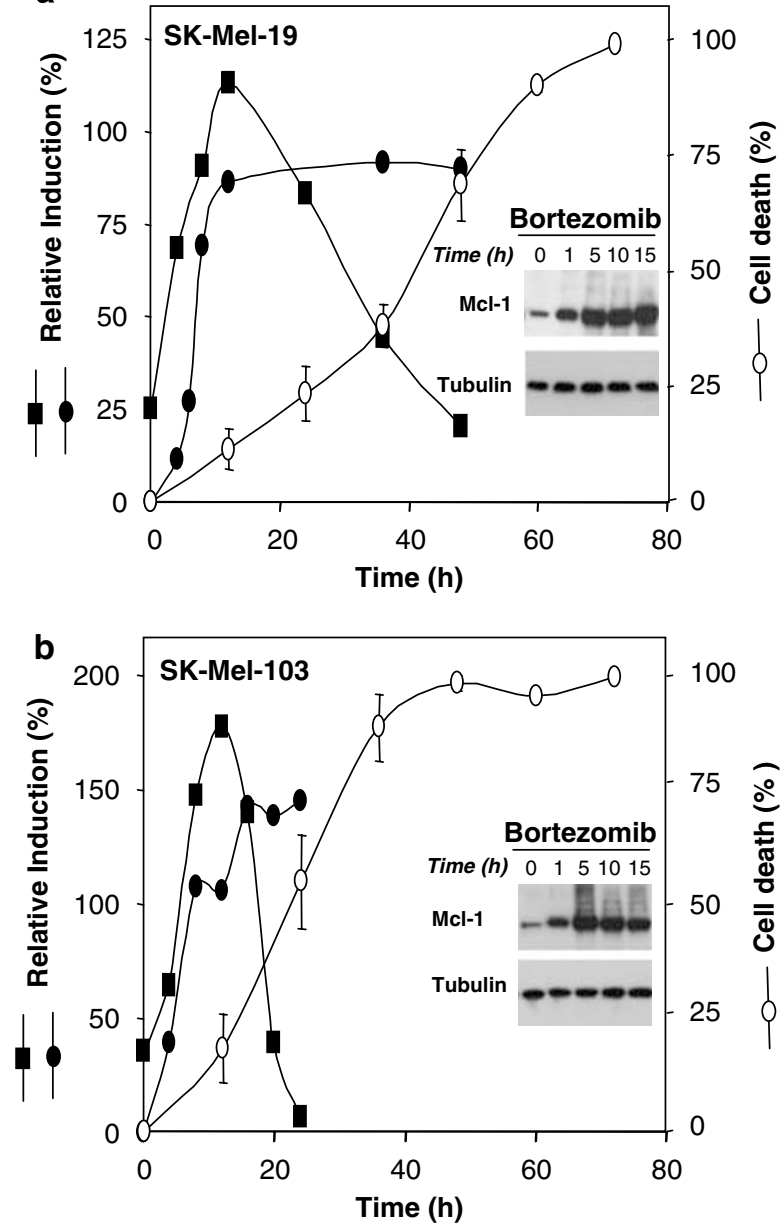

C

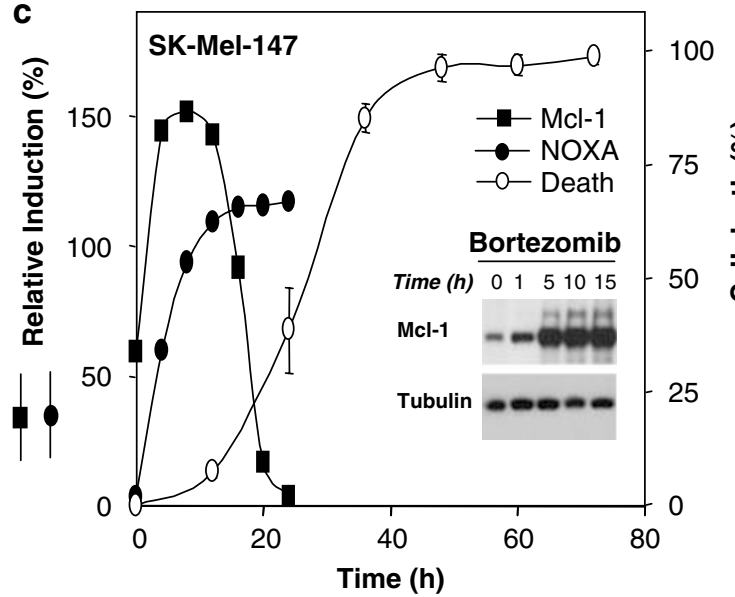

d

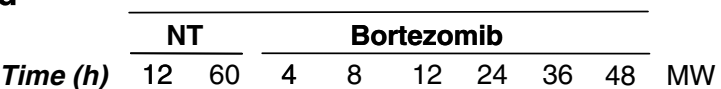

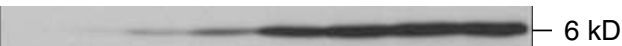

NOXA

Mcl-1

Bcl-2

Casp-9

Casp-8

Casp-3

Casp-7

Tubulin

e

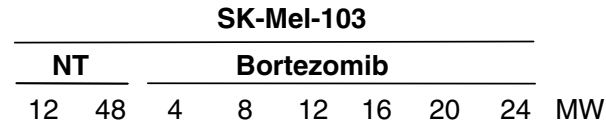

Time (h)

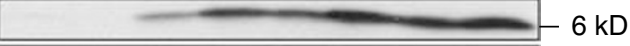

Mcl-1

$\mathrm{Bcl}-2$

$\mathrm{Bcl}-\mathrm{x}_{\mathrm{L}}$

Casp-9

Casp-8

Casp-3

Casp-7

Tubulin

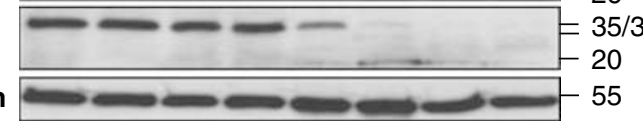

$\mathbf{f}$

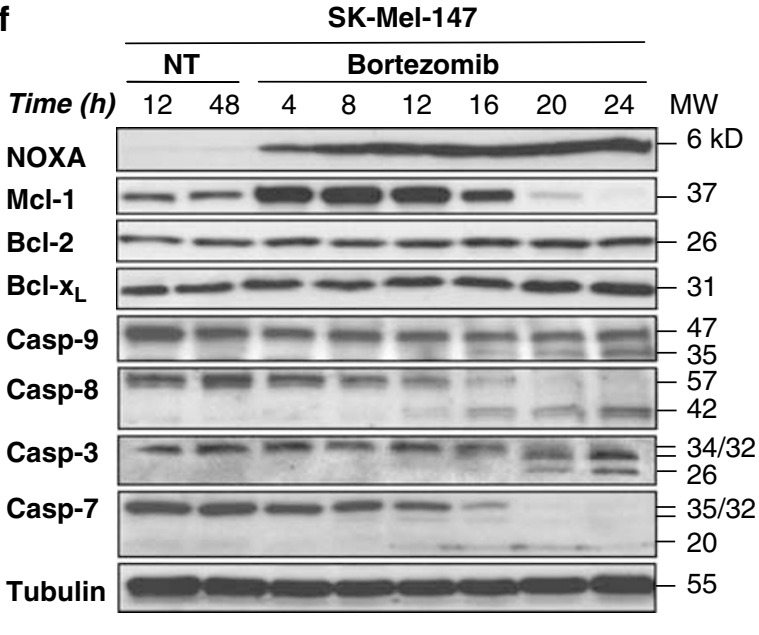

Figure 1 Impact of bortezomib on regulators and effectors of programmed cell death. (a-c) Comparative analysis of cell death (white circles) and accumulation of NOXA and Mcl-1 (black circles and black squares, respectively), in SK-Mel-19 (a), SK-Mel-103 (b) and SK-Mel-147 (c) induced by 50 nM bortezomib in standard culture conditions. Cell death was determined by trypan blue exclusion assay. Insets correspond to immunoblots showing the relative accumulation of NOXA and Mcl-1 at different time points upon addition of bortezomib. (d-f) Early induction of NOXA, but delayed caspase processing in melanoma cells treated with bortezomib estimated by protein immublotting. Tubulin is used as a loading control. Arrows point to processed caspases. In this, and other figure legends, NT stands for cells treated with vehicle control $(0.025 \%$ DMSO) 
a
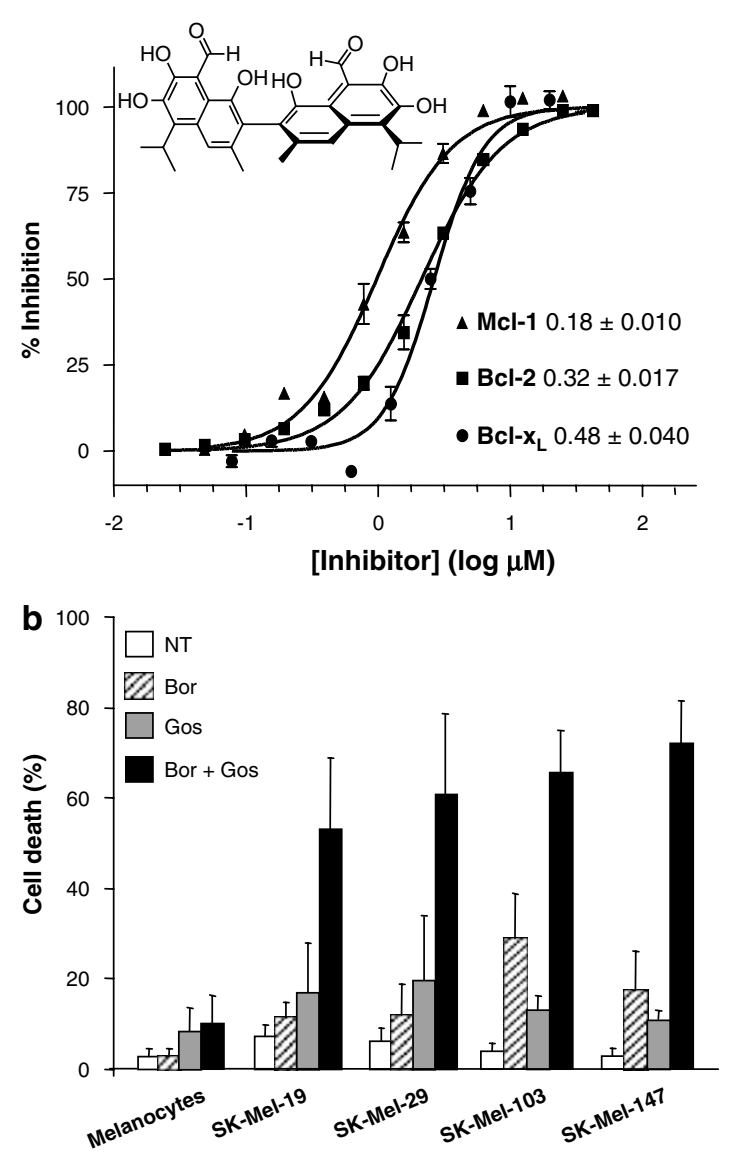

C
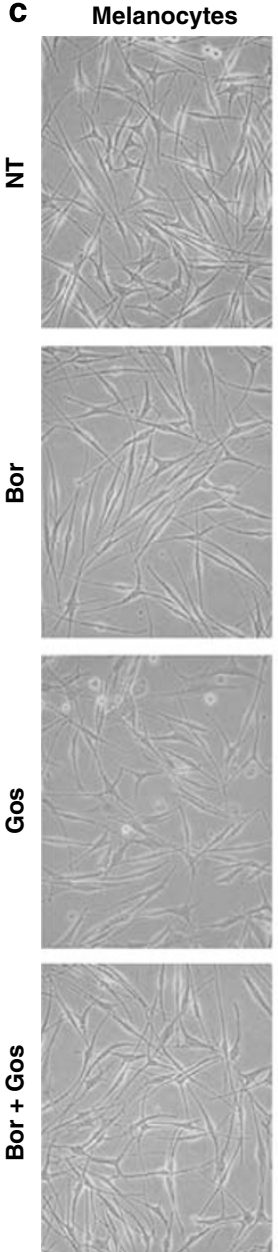

SK-Mel-103
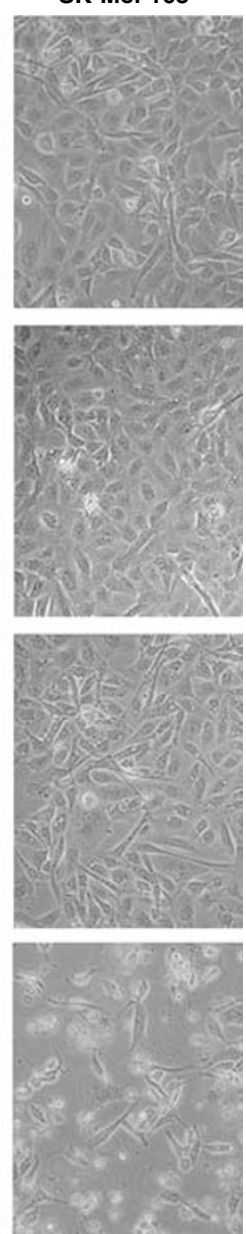

Figure 2 (-)-Gossypol, a BH3 mimetic, augments bortezomib-mediated melanoma cell killing in vitro. (a) Estimation of inhibitory constants $\left(K_{\mathrm{i}}\right)$. Inhibition of $\mathrm{Bcl}-2$, Bcl- $\mathrm{x}_{\mathrm{L}}$ and $\mathrm{Mcl}-1$ proteins in vitro, based on fluorescence polarization in a competitive binding assay using a fluorescently labeled peptide corresponding to the $\mathrm{BH} 3$ domain of Bim (FAM-Bid-BH3). Values for Bcl-2, Bcl- $x_{\llcorner}$or Mcl-1 protein bound to FAM-Bid-BH3 in the absence of gossypol defined the maximal fluorescence polarization ( $0 \%$ inhibition). The molecular structure of gossypol is shown in the inset. Binding affinities correspond to $K_{\mathrm{i}}$ values $(\mu \mathrm{M})$ for the indicated Bcl-2 family members. (b) The effect of $(-)$-gossypol and bortezomib, as single agents or combination, on foreskin melanocytes and a panel of melanoma cell lines in culture. Cells were treated with $10 \mathrm{nM}$ bortezomib (Bor) and/or $1 \mu \mathrm{M}(-)$-gossypol (Gos), for $36 \mathrm{~h}$, and cell death was assessed by trypan blue exclusion. (c) Representative micrographs of the indicated cell populations treated as in (b). Note the lack of effect of the bortezomib/(-)-gossypol combination on the morphology or cell density of normal melanocytes

started to proliferate actively ( $48 \mathrm{~h}$ after the s.c. implantations and $72 \mathrm{~h}$ after the i.v. injections). ${ }^{6}$ Bortezomib and (-)gossypol were administered systemically at concentrations below their described maximum tolerated dose (see Materials and methods).

Bortezomib was able to reduce growth of the SK-Mel-103 s.c. xenografts (see representative examples in Figure $3 a$ and quantification in Figure $3 b$ ). However, as previously described, ${ }^{6}$ this effect was not statistically significant $(P=0.190)$. Tumor growth was also delayed by $(-)$-gossypol $(P=0.043)$. However, the combination of $(-)$-gossypol and bortezomib was significantly more potent than each agent alone $(P=0.005$; Figure $3 a$ and $b)$.

While these results are encouraging, the impact of the drug combinations on the control of metastatic dissemination is perhaps more relevant, since metastasis is the leading cause of death in melanoma patients. ${ }^{1-3}$ The $(-)$-gossypol/bortezomib combination provided a significant reduction in metastatic growth of SK-Mel-103 and SK-Mel-147 (Figure 3c and d). Consequently, the antitumor effect of bortezomib/(-)gossypol improved overall survival. By day 17 of treatment, more than $70 \%$ of control mice had either died or were moribund as result of significant respiratory complications. In contrast, no deaths occurred in the (-)-gossypol/bortezomib combination group, and these mice showed no signs of discomfort. Macroscopic analyses of lungs implanted with cell line SK-Mel-147 revealed a reduced size and number of metastatic nodules after treatment with both drugs (Figure $3 \mathrm{c}$ and $\mathrm{d}$ ). The average number of metastatic lung nodules $\geqslant 2 \mathrm{~mm}$ in diameter was 50,16 and 20 per mouse, in animals treated with placebo control, bortezomib or (-)-gossypol as single agents, respectively (Figure 3c). However, only an average of three metastases $\geqslant 2 \mathrm{~mm}$ were detected per mouse in the group treated with the bortezomib/(-)-gossypol combination $(P=0.001$; see representative examples of lungs visualized by fluorescence-based imaging in 

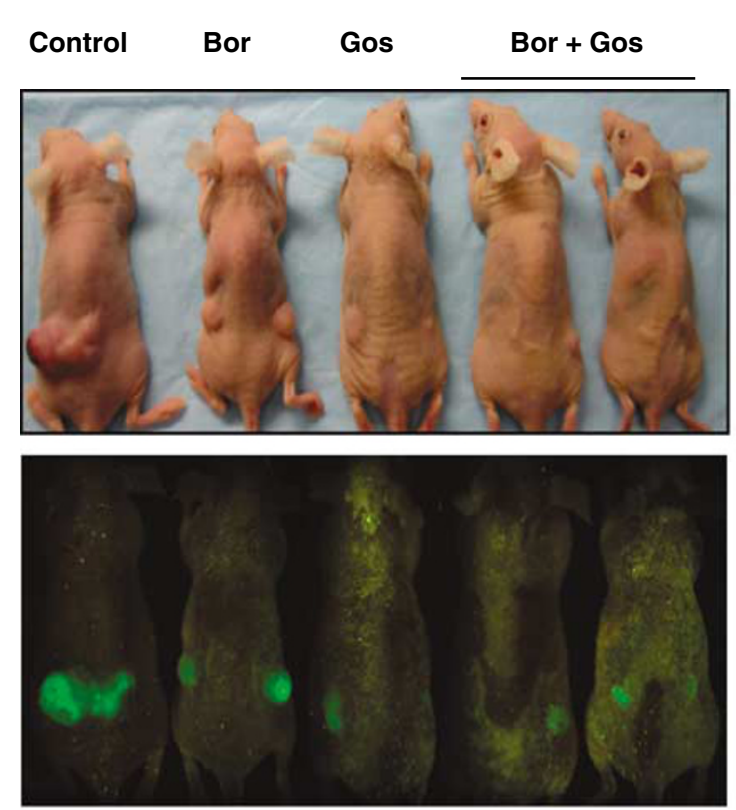

d

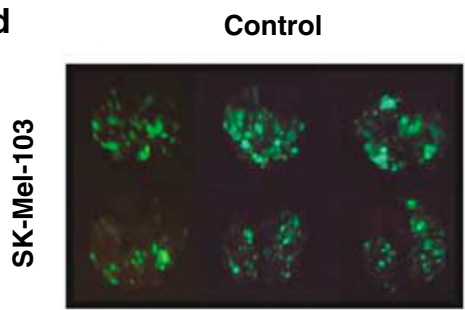

守

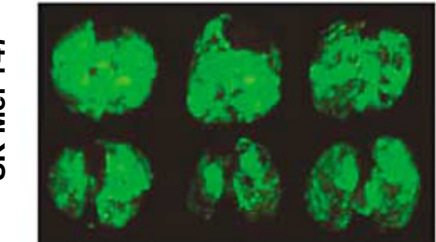

b 250
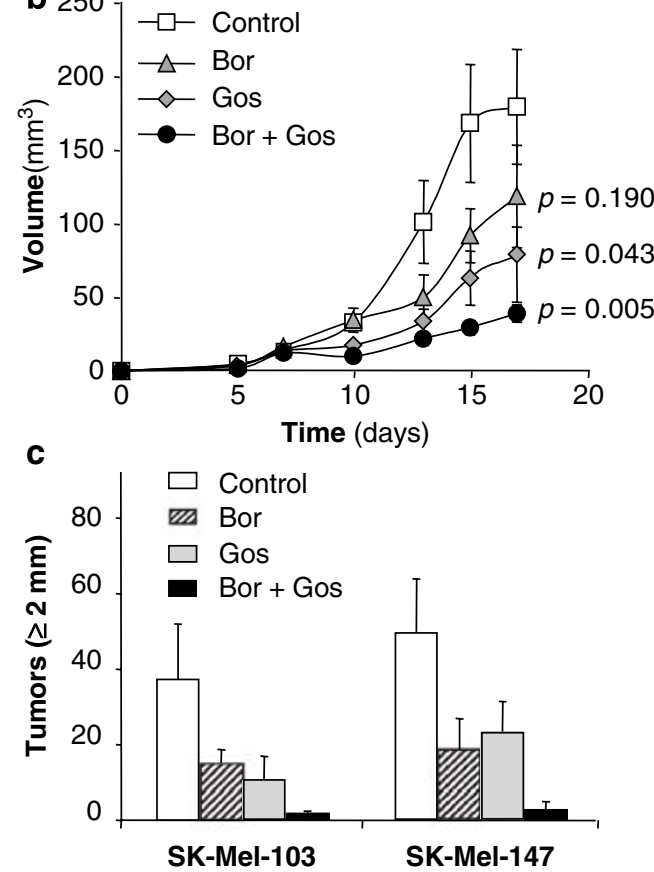

Gossypol

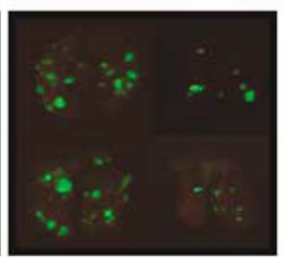

Bortezomib + Gossypol

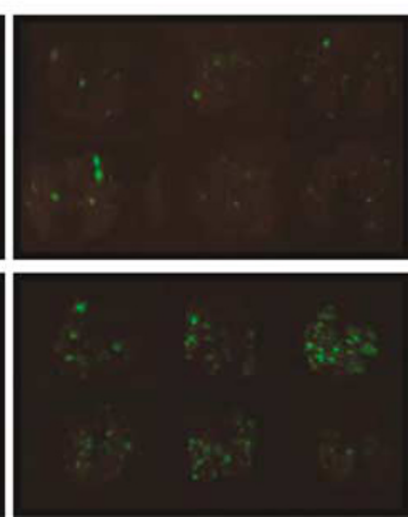

Figure 3 Gossypol augments the antitumor effect of bortezomib against melanoma in vivo. (a) Photographs of mice inoculated s.c. with GFP-tagged SK-Mel-103 and imaged with visible light (upper panels) or by fluorescence imaging (bottom panels) at day 17 of treatment with placebo control, bortezomib (Bor), (-)-gossypol (Gos) or a combination of both agents. Quantification of tumor growth is shown in (b). (c) Analysis of the impact of (-)-gossypol and bortezomib, as single agents or combination in a surrogate model of melanoma metastasis. Indicated is the number of metastatic lung nodules $\geqslant 2 \mathrm{~mm}$ in diameter observed at day 17 post treatment in mice inoculated i.v. with SK-Mel-103 or SK-Mel-147. (d) Representative fluorescence photographs of lungs from animals inoculated with SK-Mel-103 or SK-Mel-147, and treated with the indicated compounds. Note the reduced number and size of tumor nodules provided by the bortezomib/(-)-gossypol combination

Figure 3d). The impact of the drug combination was also evident, although less pronounced, against SK-Mel-103 (Figure $3 c$ and $d$ and results not shown). Given the poor efficacy of conventional chemotherapeutic agents, our results could have important translational implications.

\section{Genetic analysis of the contribution of antiapoptotic $\mathrm{Bcl}-2$ proteins to tumor cell survival after proteasomal inhibition: RNA interference}

A variety of biochemical and mechanistic analyses in multiple cancer types have demonstrated the antitumoral activity of (-)-gossypol, primarily linked to its role as a $\mathrm{BH} 3$ mimetic.
However, dysregulation of mitochondrial and redox-dependent functions by gossypol can affect, directly or indirectly, other cellular processes ${ }^{23}$ that may act in a BAX/BAK independent manner. ${ }^{28,29}$ Therefore, a genetic approach utilizing RNA interference was developed to validate the BH3-dependent function of (-)-gossypol, and to establish the hierarchical requirement of various Bcl-2 family members for viability upon bortezomib treatment. Specifically, short hairpins against unique regions of $\mathrm{Mcl}-1, \mathrm{Bcl}-\mathrm{x}_{\mathrm{L}}$ or $\mathrm{Bcl}-2$ were cloned into an eGFP-expressing lentiviral vector to generate short hairpin RNAs (shRNAs) (Figure 4a; see Materials and methods and Verhaegen et al. ${ }^{30}$ for additional information). As shown in Figure 4b, this technique allows for a nearly 
a

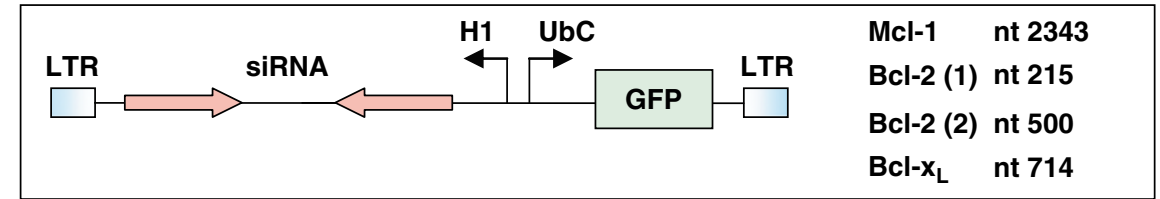

b

Control
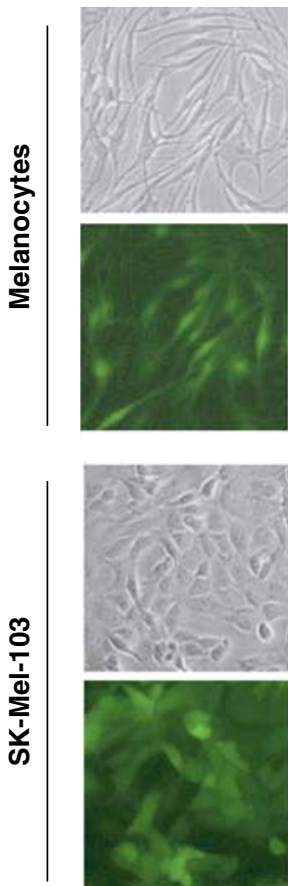

C
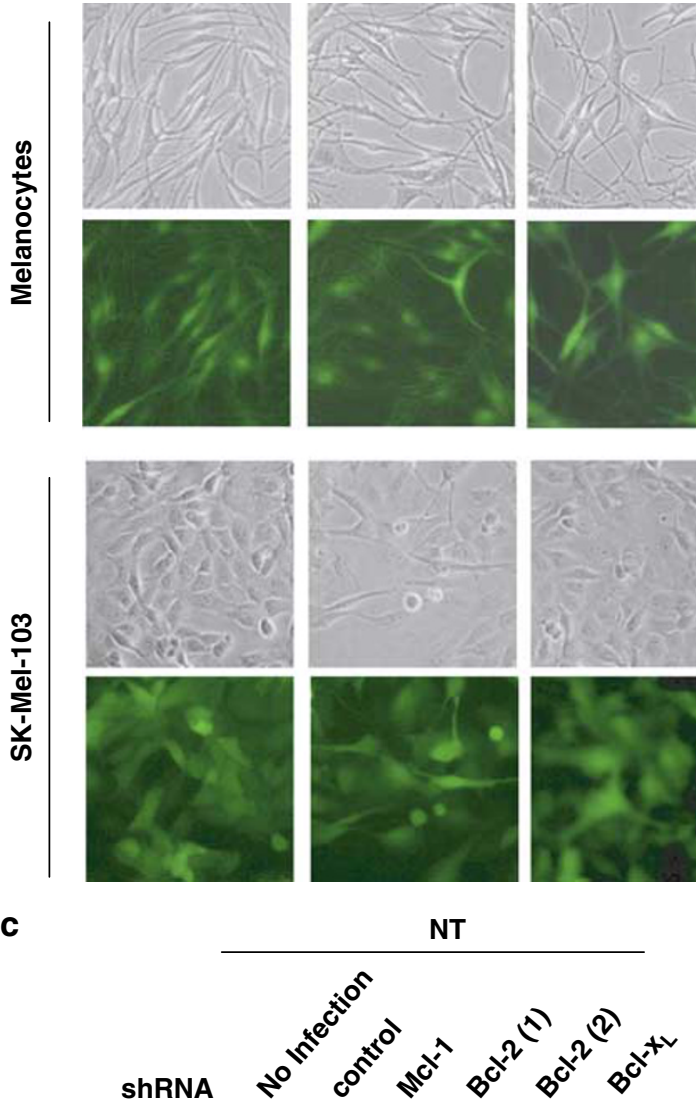

Bcl-2 (2)
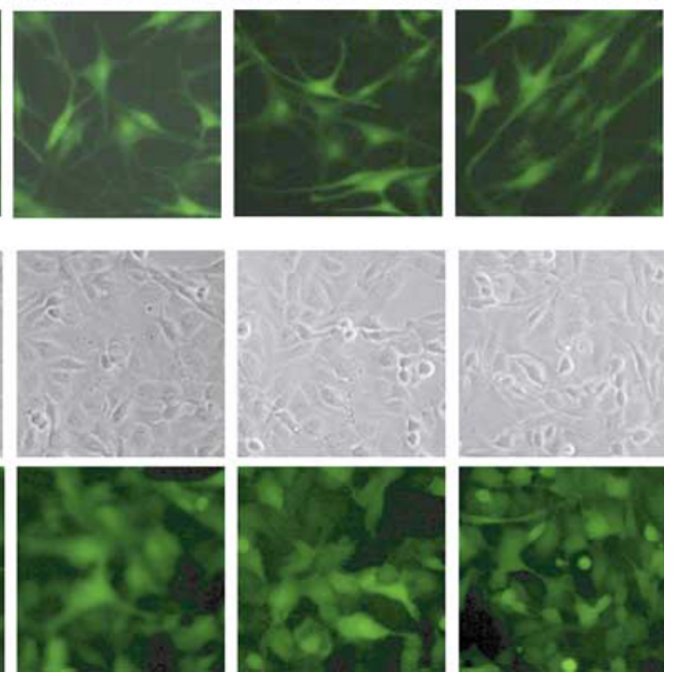

Bortezomib

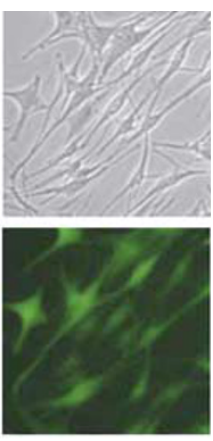

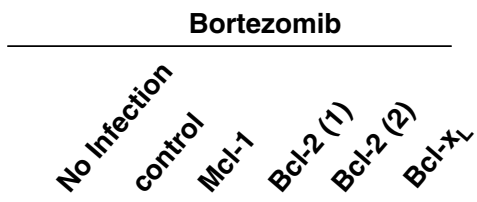
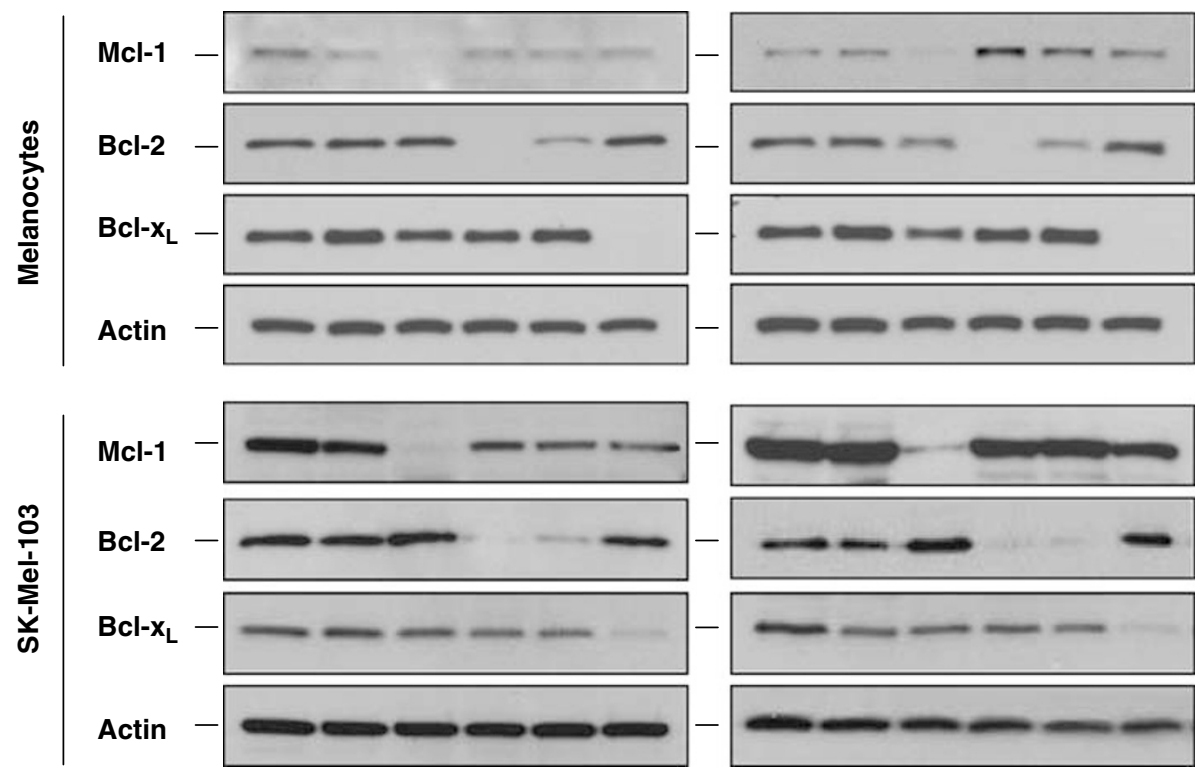
complete infection of melanocytes and melanoma cells (i.e. $>95 \%$ cells are GFP positive within 2 days after infection). The efficacy and selectivity of this approach is shown in Figure 4c (left panels corresponding to melanocytes and right panels to representative melanoma cells). A reduction of $>80 \%$ for $\mathrm{Mcl}-1, \mathrm{Bcl}-\mathrm{x}_{\mathrm{L}}$ or $\mathrm{Bcl}-2$ could be achieved without effecting the expression of other $\mathrm{Bcl}-2$ proteins.

Differential impact of Mcl-1, Bcl- $\mathrm{x}_{\mathrm{L}}$ and $\mathrm{Bcl}-2$ on the resistance of melanoma cells to bortezomib. Long-term downregulation of either $\mathrm{Bcl}-2$ or $\mathrm{Bcl}-\mathrm{x}_{\mathrm{L}}$ can induce cell death in melanocytes. ${ }^{31,32}$ However, temporal inactivation of these genes by the shRNAs indicated above (mimicking acute treatments typical of clinical trials) was well tolerated by both melanocytes and melanoma cells (Figure 4b). Mcl-1 shRNA was also non-toxic for melanocytes (Figure 4b). Therefore, isogenic series of normal melanocytes, and of SK-Mel-19, SK-Mel-103 and SK-Mel-147 (generated by specific inactivation of $\mathrm{Mcl}-1, \mathrm{Bcl}-\mathrm{x}_{\mathrm{L}}$ or $\left.\mathrm{Bcl}-2\right)$, were used to assess the hierarchical contributions of Bcl-2 family members to bortezomib resistance. The different populations were treated with sublethal doses of bortezomib, and cell death was determined by trypan blue exclusion at various time points. The reduction of $\mathrm{Mcl}-1$ levels was shown to have a dramatic impact on the kinetics and final extent of bortezomib-induced cell death (Figure 5a). For example, while more than $50 \mathrm{~h}$ were required to kill $70 \%$ of the parental SK-Mel-19 cell line (Figure 1a), a similar extent of cell death could be achieved by $18 \mathrm{~h}$ when $\mathrm{Mcl}-1$ was downregulated (Figure 5a). Even in cells from lines SK-Mel-103 or SK-Mel147, which are intrinsically sensitive to bortezomib, Mcl-1 downregulation had a significant effect (i.e. death rates observed by $18 \mathrm{~h}$ in $\mathrm{Mcl}-1$-expressing cells could be achieved as early as $6 \mathrm{~h}$ when $\mathrm{Mcl}-1$ was downregulated; Figure 5a). Analysis of cytochrome $c($ Cyt $c)$ release from the mitochondria confirms the acceleration of apoptosis (Figure 5b). Considering the potent antiapoptotic effect of $\mathrm{Bcl}-2$ in response to standard chemotherapeutic agents, ${ }^{33}$ its downregulation was surprisingly ineffective in favoring bortezomib-induced cell death. Neither SK-Mel-19, SK-Mel103 nor SK-Mel-147 showed an altered response to bortezomib when Bcl-2 was downregulated by shRNA (Figure 5a). Bcl- $x_{\mathrm{L}}$ downregulation, however, caused a noticeable acceleration of the killing by bortezomib in all three lines (Figure 5a; see Supplementary Figure 1 for visualization of cell detachment). Therefore, these results indicate that, in addition to $\mathrm{Mcl}-1, \mathrm{Bcl}-\mathrm{x}_{\mathrm{L}}$, should be considered as a target to improve the efficacy of bortezomib.

The roles of $\mathrm{Mcl}-1, \mathrm{Bcl}-\mathrm{x}_{\mathrm{L}}$ and $\mathrm{Bcl}-2$ in cell survival upon proteasome inhibition were also studied in normal melanocytes. In these cells, any of these three proteins could be downregulated (Figure 4c) without compromising cell viability upon treatment (Figure $5 \mathrm{a}$, see also representative micrographs in
Supplementary Figure 1). Altogether, these results support a differential requirement of $\mathrm{Bcl}-2$ family members for the survival of melanocytes versus malignant melanoma cells.

Targeted activation of the apoptotic machinery in aggressive melanoma cells. $\mathrm{Bcl}-\mathrm{x}_{\mathrm{L}}$ and $\mathrm{Mcl}-1$ can control caspase-dependent and independent mechanisms of cell death. To address the consequence of inactivation of these proteins in the response to bortezomib, SK-Mel-19 and SKMel-103 were transduced (by lentiviral infection) with shRNAs for Mcl-1, Bcl-xL or Bcl-2. Two days after infection, cells were treated with low doses of bortezomib, and protein extracts analyzed by immunoblotting. Consistent with its low impact on cell viability, Bcl-2 shRNA had no impact on caspase cleavage upon bortezomib treatment (Figure 6a). However, the downregulation of $\mathrm{Bcl}-\mathrm{x}_{\mathrm{L}}$ and, particularly, of Mcl-1 markedly accelerated caspase processing (Figure 6a; see quantification in Supplementary Figure 2). Similarly, compare the minimal cleavage of the effector casp-3 and -7 in SK-Mel-19 control cells at $18 \mathrm{~h}$ of bortezomib treatment, with $\geqslant 80 \%$ processing in their Mcl-1deficient counterparts (Figure $6 \mathrm{a}$ and Supplementary Figure 2). Consistent with feedback loops involving the intrinsic and extrinsic pathways in bortezomib-treated cells, ${ }^{9}$ the processing of casp- 8 was also accelerated by Mcl- 1 shRNA interference. $\mathrm{Mcl}-1$ inactivation was likewise the most potent in promoting caspase processing in the more sensitive SKMel-103 (Figure 6a and Supplementary Figure 3).

In addition to NOXA, Mcl-1 can bind other proteins in the $\mathrm{Bcl}-2$ family. Currently, there is an active debate regarding how pro- and antiapoptotic proteins of this family are interregulated to control mitochondrial-dependent death programs. $^{34,35}$ To assess the specific contribution of NOXA to the increased response to bortezomib following Mcl-1 downregulation, we again exploited RNA interference. We infected melanoma cells with a lentivirus coding for a highly efficient shRNA against NOXA, ${ }^{6}$ which is able to abrogate even the massive accumulation of this protein upon proteasome inhibition (see examples in Figure 6b). As shown in Figure 6c, blockade of NOXA in SK-Mel-19 compromised the stimulatory effect of $\mathrm{Mcl}-1$ downregulation, reducing the amount of cell death to levels below the parental controls. These effects were found across a range of bortezomib dosages and different treatment times (Figure 6b, and results not shown). Altogether, shRNA interference affords novel insights into the activation of the intrinsic apoptotic machinery in melanoma cells, which are impervious to standard chemotherapeutic agents.

\section{Discussion}

In this study, we utilized genetic and pharmacological approaches to identify intrinsic mechanisms of resistance to

Figure 4 Specific knockdown of Bcl-2 family members by highly efficient and selective lentiviral-driven shRNA. (a) Schematic representation of the lentiviral vector used for RNA interference. shRNA is driven by the H1 RNA promoter and the reporter GFP by the ubiquitin- $\mathrm{C}$ promoter. The $5^{\prime}$ positions of the $19 \mathrm{bp}$ sequences of human $B C l-2, B C l-x_{L}$ and $\mathrm{MCl}-1$ targeted by the shRNAs, are listed on the right. (b) Brightfield and fluorescence photomicrographs of primary human melanocytes or SK-Mel-103 melanoma cells infected with the shRNA lentiviral constructs, or a control construct encoding a scrambled sequence. The high infection efficiency was confirmed by $>90 \%$ GFP-positive cells. (c) PAGE-SDS immunoblotting demonstrating the efficacy and selectivity of $\mathrm{Bcl}-2, \mathrm{Bcl}-\mathrm{x}_{\mathrm{L}}$ or $\mathrm{Mcl}-1$ downregulation. Actin is shown as a loading control 
a
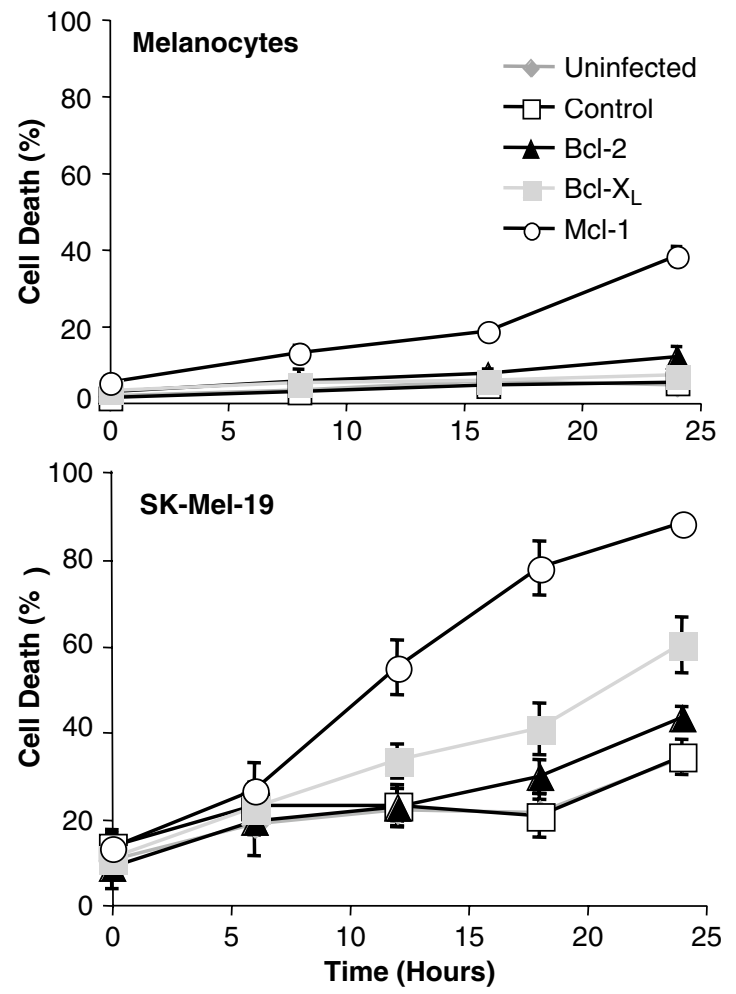
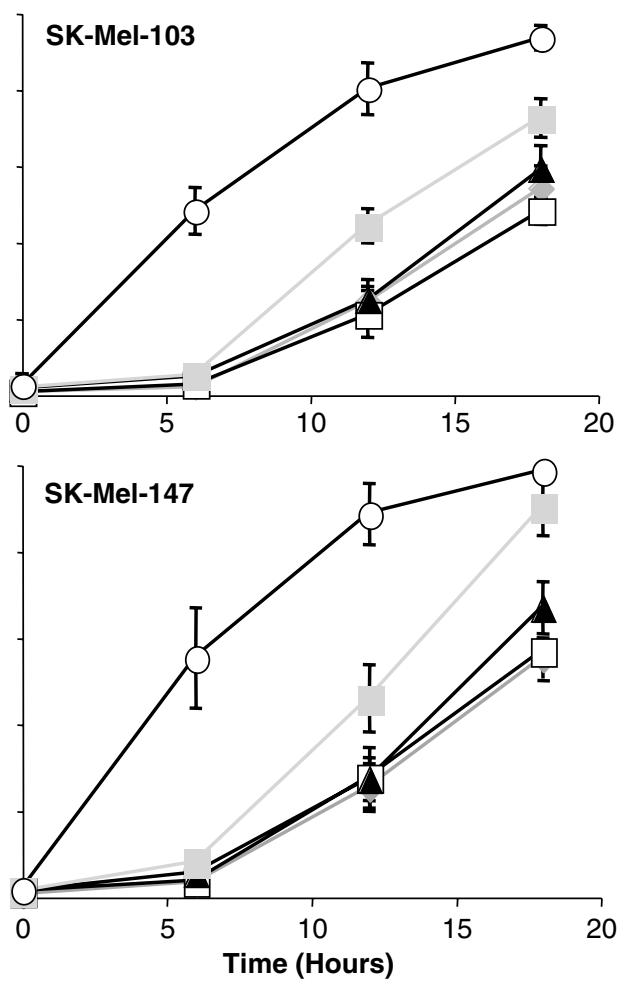

b

shRNA Constructs

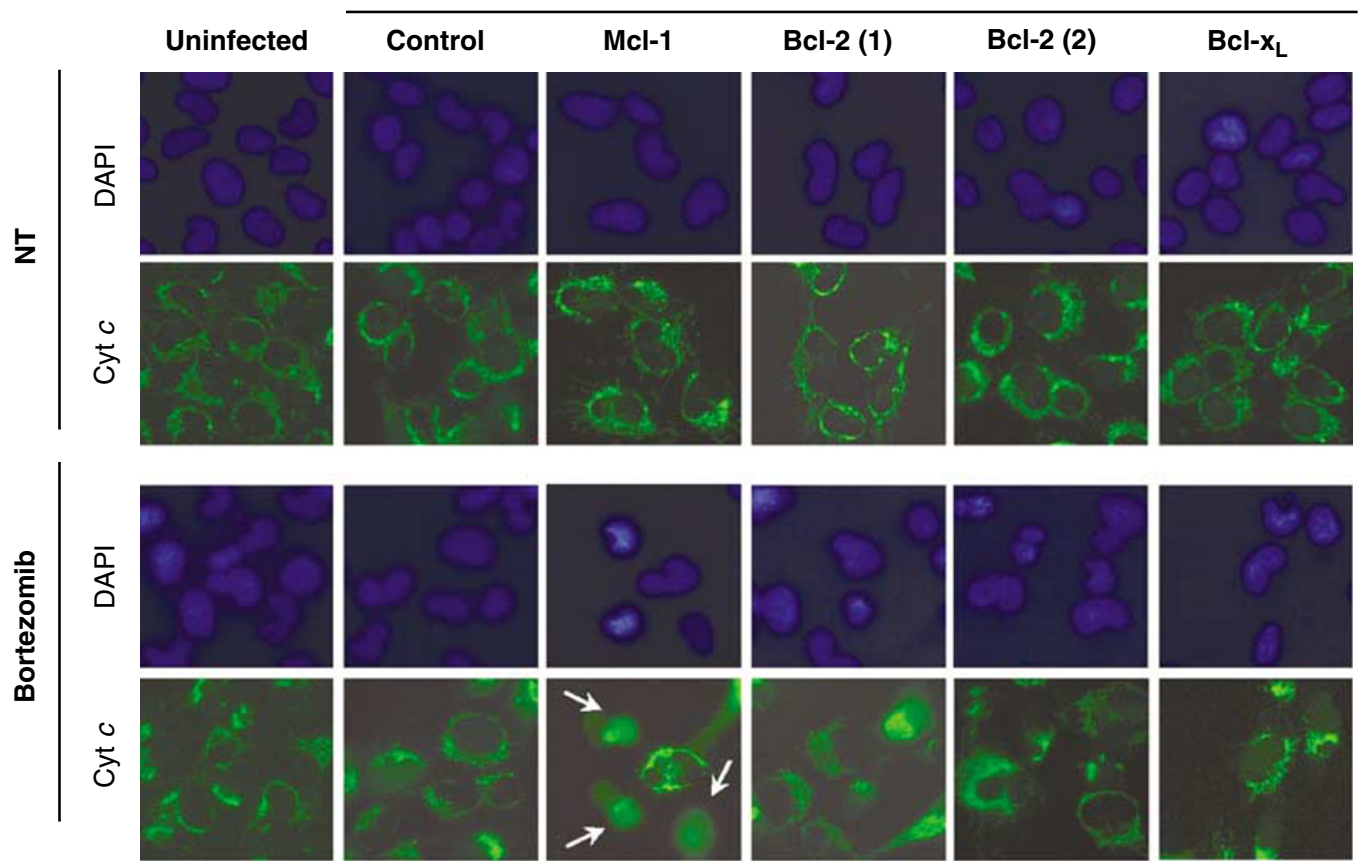

Figure 5 Functional impact of inactivation of $\mathrm{Bcl}-2$ family members by RNA interference, and identification of $\mathrm{Mcl}-1$ and $\mathrm{Bcl}-\mathrm{x}_{\mathrm{L}}$ as primary mediators of the resistance to bortezomib-induced apoptosis. (a) Kinetic analysis of cell death measured by trypan blue exclusion after incubation of the indicated isogenic subpopulations of melanocytes or melanoma cells (SK-Mel-19, SK-Mel-103 and SK-Mel-147) with $50 \mathrm{nM}$ bortezomib. (b) Release of Cyt $c$. The corresponding isogenic SK-Mel-103 subpopulations expressing scrambled shRNA or shRNA against Mcl-1, Bcl-X or Bcl-2 were left untreated or treated with $50 \mathrm{nM}$ bortezomib (Bor) for $6 \mathrm{~h}$. Cells were fixed and stained with anti-Cyt $c$ antibody (green fluorescence). Nuclei were counterstained in blue with DAPI. Arrows display cells with cytosolic Cyt $c$, a hallmark of apoptosis, which is most noted in bortezomib-treated cells expressing low levels of Mcl-1

bortezomib, and provided the proof of principle for a strategy to increase the efficacy of this drug in vivo. We have identified a functional hierarchy of antiapoptotic Bcl-2 family members in maintaining cell viability after proteasome inhibition, which differs between normal melanocytes and melanoma cells. RNA interference demonstrated a tumor cell-specific require- 
a
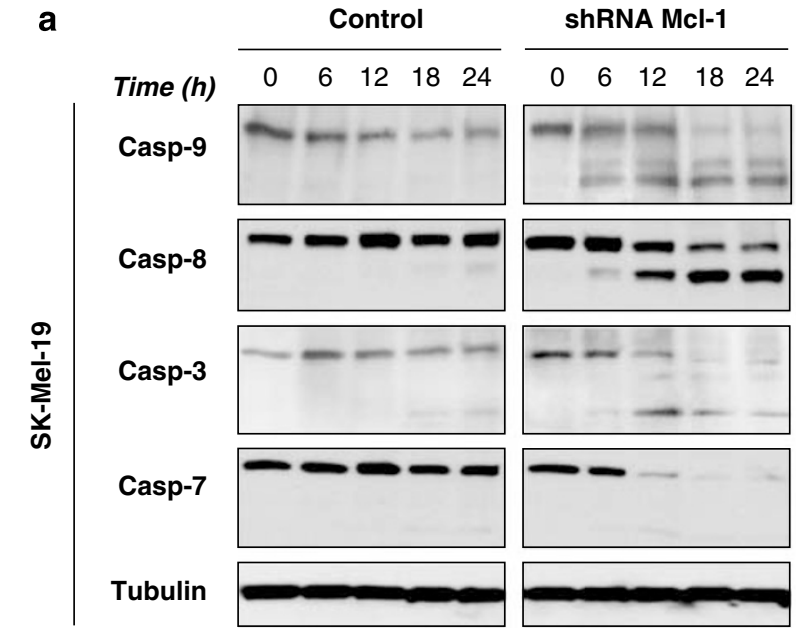
ShRNA Bcl-2(1) $\begin{array}{lllll}0 & 6 & 12 & 18 & 24\end{array}$ \begin{tabular}{lllll}
\multicolumn{4}{c}{ ShRNA Bcl- $\mathbf{x}_{\mathbf{L}}$} \\
\hline $\begin{array}{llllll}0 & 6 & 12 & 18 & 24\end{array}$ MW
\end{tabular}
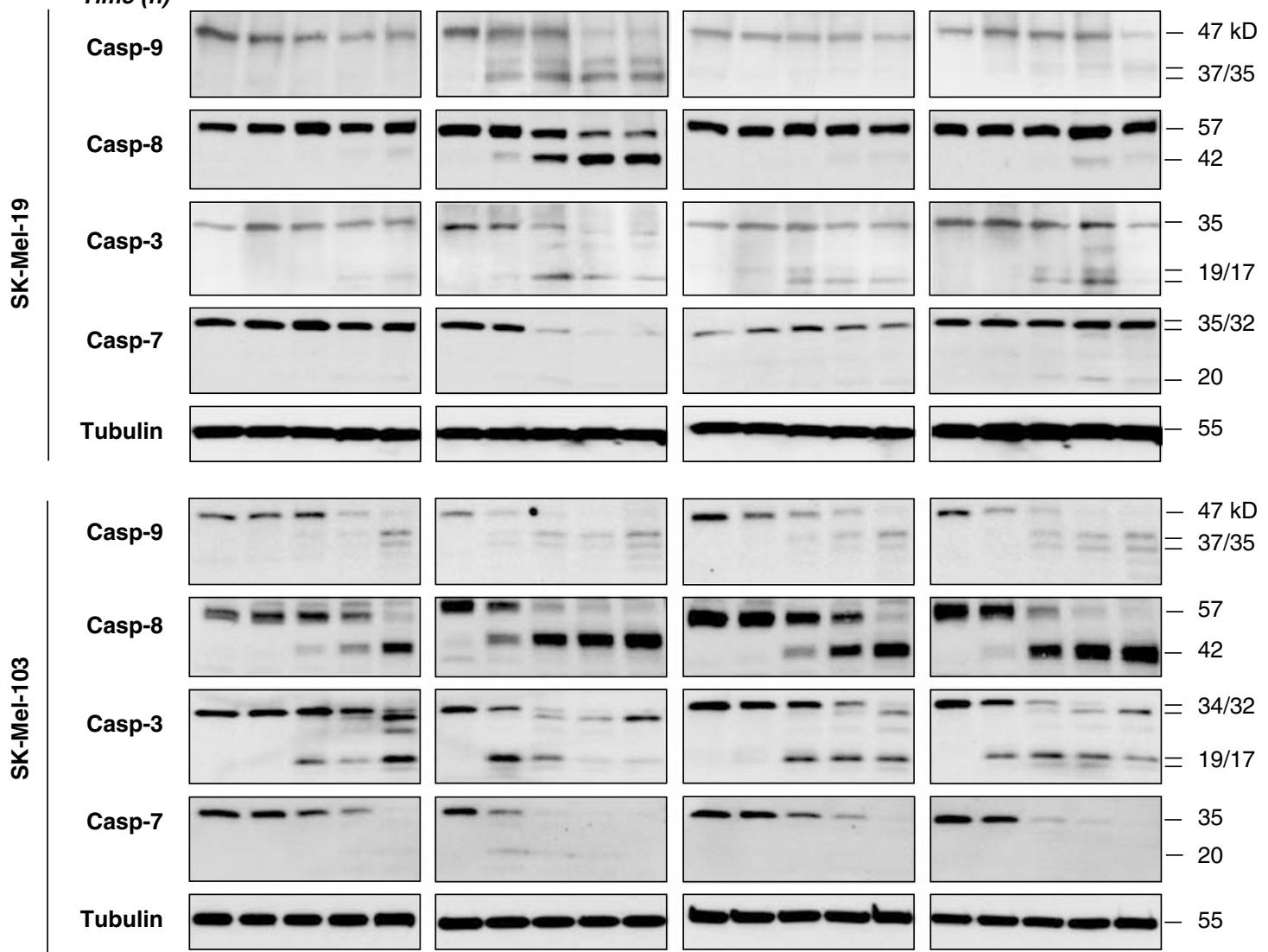

55
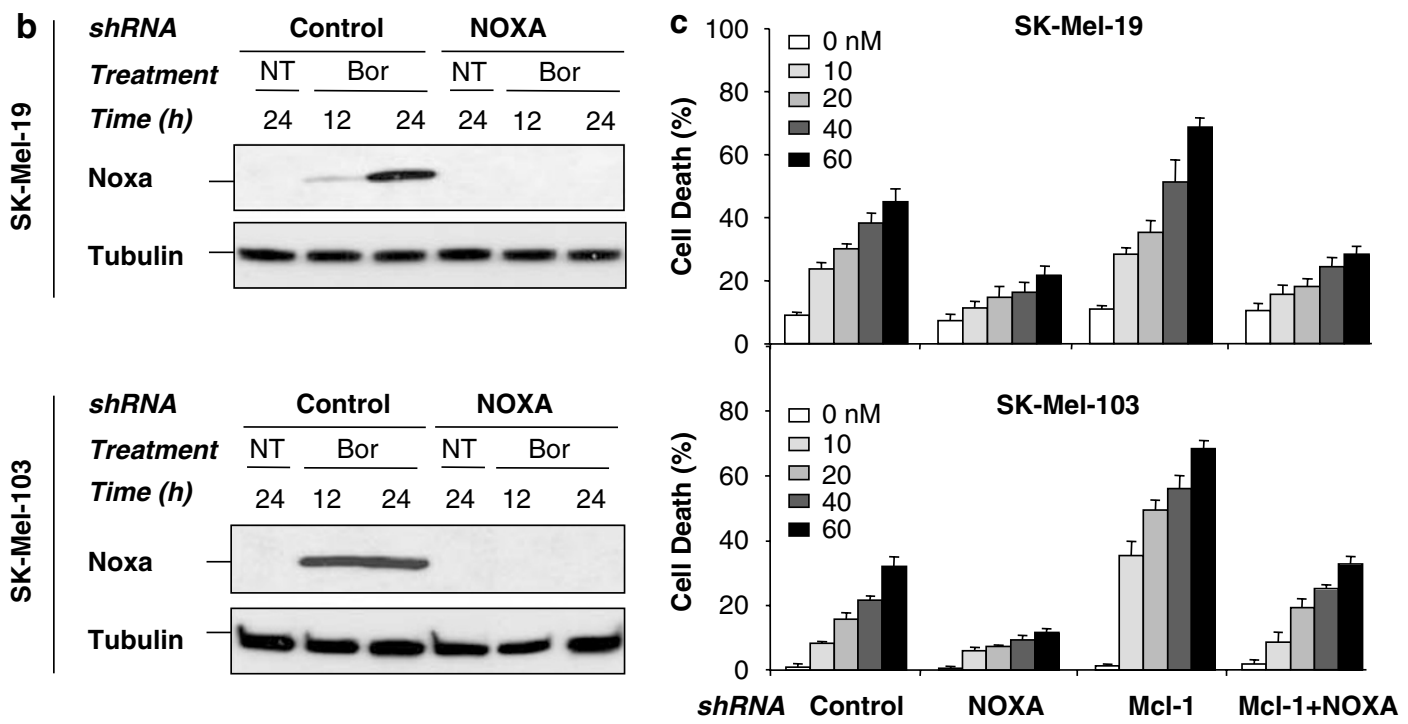

Figure 6 shRNA interference to identify genetic alterations allowing for a selective acceleration of caspase processing in melanoma cells. (a) Impact of bortezomib treatment on caspase processing. Protein immunoblots showing the processing of regulatory (casp-9 and -8) and effector caspases (casp-3 and -7) in melanoma cell lines SKMel-19 and SK-Mel-103 expressing the indicated shRNAs. Arrows point to the inactive proform of the corresponding caspases, which need to be fully processed for maximal induction of cell death (see Figure 5a). The short dashes mark the cleaved subunits. Note acceleration of caspase processing by bortezomib induced by shRNAs against Mcl1, and to a lower extent Bcl- $x_{L}$, but not Bcl-2 (see quantification in Supplementary Figure 2). (b) Generation of NOXA-deficient cells by shRNA. Blots correspond to extracts isolated 3 days after infection of SK-Mel-19 or SK-Mel-103 with NOXA-shRNA-expressing lentivirus. (c) Response of the indicated cell populations to increasing doses of bortezomib (nM concentration). Data represent average \pm S.E. from three experiments, estimated $18 \mathrm{~h}$ after treatment of SK-Mel-19 and $12 \mathrm{~h}$ after treatment of SK-Mel-103 
ment for Mcl-1 and, to a lesser extent, for $\mathrm{Bcl}-\mathrm{x}_{\mathrm{L}}$ in resisting bortezomib. However, both of these proteins are largely dispensable to normal melanocytes after bortezomib treatment, offering a window for therapeutic intervention.

From a translational point of view, compounds able to minimize the time delay from proteasomal inhibition to the activation of the apoptotic machinery in a tumor cell-selective manner could have important implications. In clinical practice, to limit secondary toxicity, proteasome inhibition by bortezomib is neither complete nor sustained. ${ }^{9}$ Bortezomib is typically administered by bolus injection, leaving residual proteasomal activity of $20-30 \%$ and allowing for recovery between treatment cycles. Moreover, pharmacokinetic analyses indicate that bortezomib is rapidly inactivated by hepatic detoxification. $^{36}$ Therefore, there is interest in compounds that can act in a synergistic manner with bortezomib without compromising the viability of normal cells. This need is particularly important in metastatic melanoma patients, whose average survival of 6-10 months could not be improved with the current dosing and administration route of bortezomib. ${ }^{15}$

The rational design of new treatments to overcome bortezomib resistance in melanoma cells is complicated by several hurdles. First, the ubiquitin/proteasome system controls the half-life of nearly $80 \%$ of cellular proteins, both in normal and tumor cells, and no consistent predictive markers of response to bortezomib have been identified in vivo. ${ }^{9}$ Furthermore, potent proapoptotic factors such as Bim $\mathrm{EL}_{\mathrm{E}}$ can be induced by proteasome inhibition in melanocytes as efficiently as in their tumor counterparts ${ }^{5}$ (Figure 7). Therefore, normal cell compartments may be inherently 'at risk' of stress driven by proteasome inhibition, and thus rely on mechanisms of protection to maintain their viability.

An additional barrier to drug development in melanoma is a complex genetic background with defects in all known survival pathways capable of blocking apoptosis upstream and downstream of the mitochondria. In particular, $\mathrm{Bcl}-2, \mathrm{Bcl}-\mathrm{x}_{\mathrm{L}}$ and $\mathrm{Mcl}-1$ can play key roles in controlling both caspasedependent and independent pathways in response to a variety of chemotherapeutic agents. The functional hierarchy of these antiapoptotic factors, and their ultimate mechanism of action in the control of melanoma cell maintenance, is unclear. The interplay between pro- and antiapoptotic members of this family is under debate in multiple systems (reviewed by Green $^{34}$ and Youle ${ }^{35}$ ). According to the so-called 'displacement model', $\mathrm{Mcl}-1, \mathrm{Bcl}-2$ and $\mathrm{Bcl}-\mathrm{x}_{\mathrm{L}}$ directly inhibit proapoptotic $\mathrm{BAX}$ and/or $\mathrm{BAK}^{37}$ In this case, competitive $\mathrm{BH} 3$ mimetics, or strategies to efficiently block $\mathrm{Mcl}-1 / \mathrm{Bcl}-2 / \mathrm{Bcl}-\mathrm{x}_{\mathrm{L}}$ function, are sufficient to engage mitochondrial dysfunction.

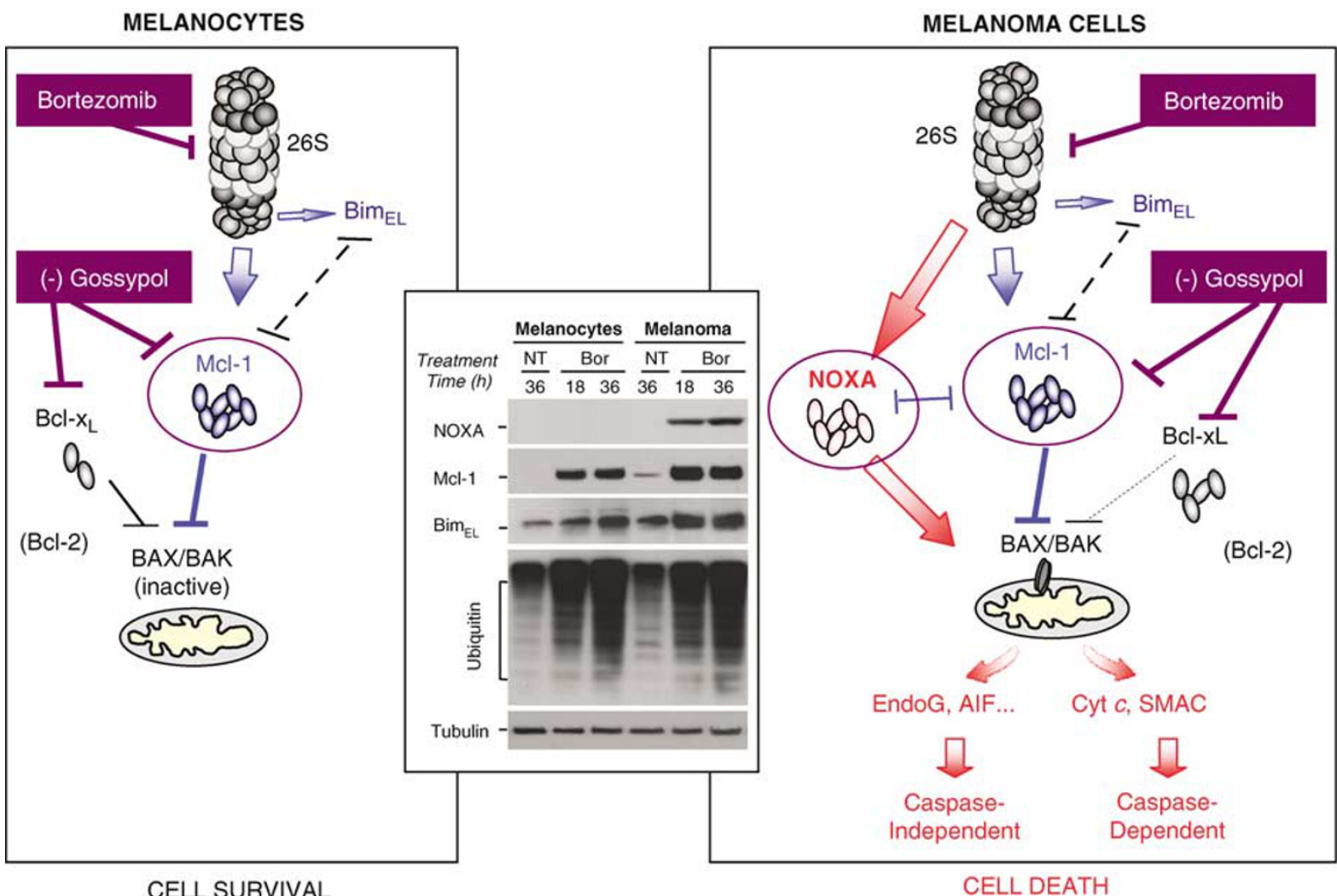

Figure 7 Differential regulation and requirement of $\mathrm{Bcl}-2$ family members in melanoma cells and melanocytes treated with bortezomib. Bcl-2 family members can be grouped in three categories depending on their regulation by the proteasome: (i) Proteasome independent (e.g. Bcl-2, Bcl-- $\mathrm{K}_{\mathrm{L}}, \mathrm{BAX}, \mathrm{BAK}$; here depicted in black); (ii) regulated by the proteasome in a tumor cell-specific manner (NOXA; shown in red); and (iii) controlled by the proteasome in normal and tumor cells (e.g. Mcl-1 and Bim $\mathrm{EL}$; shown in blue). Surprisingly, despite the significant induction of $\mathrm{Bim}_{\mathrm{EL}}$ in melanocytes, these cells are largely independent of $\mathrm{Mcl}-1, \mathrm{BCl}-\mathrm{x}_{\mathrm{L}}$ or $\mathrm{Bcl}-2$ for survival. Melanoma cells, however, significantly die if Mcl-1 is removed. A noticeable acceleration of cell death is also found by blocking Bcl- $\mathrm{x}_{\mathrm{L}}$. However, Bcl-2 was dispensable for the viability of bortezomibtreatment melanoma cells. These results emphasize the non-equivalent functional requirement of Bcl-2 family members in normal melanocytes and melanoma cells that can be exploited for rational drug design 
Conversely, the 'direct binding model' argues that removal of antiapoptotic proteins is insufficient, per se, to promote cell death, and that additional proapoptotic inducers are required for full activation of BAX and BAK. ${ }^{14,38,39}$ Our shRNA data are consistent with this second scenario. Thus, melanoma cells can tolerate an acute downregulation of $\mathrm{Mcl}-1, \mathrm{Bcl}-\mathrm{x}_{\mathrm{L}}$ or $\mathrm{Bcl}-2$. Bortezomib can provide the additional death signal needed, by potent, tumor-selective induction of NOXA (see model in Figure 7).

Since NOXA preferentially binds to and is countered by $\mathrm{Mcl}-$ $1^{13,14}$ it is not surprising that Mcl-1 shRNA dramatically accelerated bortezomib killing of melanoma cells. However, the fact that $\mathrm{Mcl}-1$ is dispensable for the viability of melanocytes was unexpected, considering that Mcl-1 is a main blocker of Bim $\mathrm{EL}_{\mathrm{L}}$, which is highly induced in melanocytes upon bortezomib treatment (Figure 7). In this context, it is also intriguing that neither $\mathrm{Bcl}-2$ nor $\mathrm{Bcl}-\mathrm{x}_{\mathrm{L}}$ downregulation compromise the viability of bortezomib-treated melanocytes.

Our data showing a hierarchical organization of apoptotic modulators in the response of melanoma cells to bortezomib (i.e. $\mathrm{Mcl}-1>\mathrm{Bcl}-\mathrm{x}_{\mathrm{L}} \gg \mathrm{Bcl}-2$ ) have implications for future drug design. Inactivation of $\mathrm{Bcl}-2$ or $\mathrm{Bcl}-\mathrm{x}_{\mathrm{L}}$ alone may not be sufficient to counteract resistance to proteasome inhibitors. In this context, our results provide a molecular explanation for the only modest enhancement of bortezomib-induced cell death with the $\mathrm{BH} 3$ mimetics, $\mathrm{ABT}-737^{22}$ and $\mathrm{BH} 3 \mathrm{I}-2^{\prime},{ }^{40}$ which bind poorly to $\mathrm{Mcl}-1$. Conversely, (-)-gossypol and other $\mathrm{BH} 3$ mimetics with high affinity for $\mathrm{Mcl}-1$ and $\mathrm{BCl}-\mathrm{x}_{\mathrm{L}}$ can dismantle the protective shield that halts caspase activation in melanoma cells. The significant activity of the (-)-gossypol/bortezomib combination in blocking melanoma growth in the metastatic dissemination model is encouraging, considering that these cells are invariably resistant to standard anticancer agents. Second generation $\mathrm{BH} 3$ mimetics based on gossypol are being generated with the objective of improving binding to $\mathrm{Mcl}-1 .{ }^{23}$ These new reagents may ultimately provide a longterm response in combination with bortezomib.

In summary, this study has addressed the interplay between the proteasome and key modulators of the apoptotic machinery in melanoma. Our results identify members of $\mathrm{Bcl}$ 2 family with differential regulation by the proteasome, and a differing requirement for the survival of melanocytes versus melanoma cells. We provided evidence, both in vitro and in vivo, for the design of rational combination strategies utilizing $\mathrm{BH} 3$ mimetics with high affinity for $\mathrm{Mcl}-1$ and $\mathrm{Bcl}-\mathrm{x}_{\mathrm{L}}$ to improve the efficacy of proteasome inhibition. Such agents could represent a new strategy to overcome the traditional chemoresistance of malignant melanoma.

\section{Materials and Methods}

Cells. The metastatic melanoma cell lines SK-Mel-19, SK-Mel-29, SK-Mel-103 and SK-Mel-147 were obtained from the Memorial Sloan-Kettering Cancer Center, NY, USA. These cells were cultured in Dulbecco's modified Eagles's medium (Life Technologies, Rockville, MD, USA) supplemented with $10 \%$ fetal bovine serum (Nova-Tech Inc., Grand Island, NY, USA). Human melanocytes were isolated from human neonatal foreskins as described ${ }^{6}$ and maintained in Medium 254 supplemented with melanocyte growth factors (HMG-1) containing $10 \mathrm{ng} / \mathrm{ml}$ phorbol 12-myristate 13-acetate (Cascade Biologics, Portland, OR, USA).

Reagents. Bortezomib (Velcade ${ }^{\mathrm{TM}}$; formerly PS-341) was obtained from Millennium Pharmaceuticals (Cambridge, MA, USA). For analyses in tissue culture systems, bortezomib was reconstituted in DMSO at a concentration of $0.1 \mathrm{mM}$, and for studies in vivo it was prepared in a $0.85 \%$ sterile saline solution at a concentration of $1.2 \mathrm{mg} / \mathrm{ml}$. (-)-Gossypol was synthesized as described previously. ${ }^{24}$ For oral dosing, lyophilized (-)-gossypol was resuspended in $100 \%$ ethanol, and subsequently diluted in sterile water to $10 \%$ ethanol, for a working concentration of $1.5 \mathrm{mg} / \mathrm{ml}$.

Fluorescence polarization assays. Inhibitory binding constants of (-)gossypol to purified Bcl-2, Bcl- $\mathrm{X}_{\mathrm{L}}$ and $\mathrm{Mcl}-1$ were determined by competitive fluorescence-polarization-based binding assays as described. ${ }^{30}$ In short, a Bid BH3containing peptide (residues 79-99) was labeled at the N-terminus with 6carboxyfluorescein succinimidyl ester (FAM). A $1-2.5 \mathrm{nM}$ portion of FAM-Bid peptide was preincubated with purified Bcl-2 $(40 \mathrm{nM})$ or Mcl-1 $(5 \mathrm{nM})$ in $100 \mathrm{mM}$ potassium phosphate $\mathrm{pH} 7.5 ; 100 \mu \mathrm{g} / \mathrm{ml}$ bovine gamma globulin; $0.02 \%$ sodium azide. To determine the $K_{\mathrm{i}}$ values for $\mathrm{Bcl}-\mathrm{x}_{\mathrm{L}}$, fluorescence polarization assays were

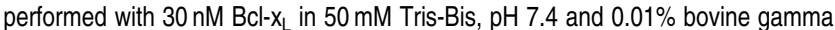
globulin. Polarization values were measured using a Ultra plate reader (Tecan US Inc., Research Triangle Park, NC, USA) in the absence or in the presence of increasing concentrations of (-)-gossypol. Excitation and emission wavelengths were set at 485 and $530 \mathrm{~nm}$, respectively. Purified protein or fluorescent probes were also included as reference controls. $K_{\mathrm{i}}$ values were calculated with GraphPad Prizm 4 software (GraphPad Software, San Diego, CA, USA) using previously described equations (http://sw16.im.med.umich.edu/software/calc_ki/). ${ }^{24}$

Protein immunoblotting. To determine changes in protein levels, $2 \times 10^{6}$ cells were treated with bortezomib $(50 \mathrm{nM})$ and harvested at the indicated time points after treatment. Total cell lysates were subjected to electrophoresis in 12, 15 or $4-15 \%$ gradient SDS gels under reducing conditions, and subsequently transferred to Immobilon-P membranes (Millipore, Bedford, MA, USA). Protein bands were detected by the ECL system (GE Healthcare, Buckinghamshire, UK). Primary antibodies included: casp- 9 and -3 from Novus Biologicals (Littleton, $\mathrm{CO}$, USA); casp-8 (Ab-3) from Oncogene Research Products (San Diego, CA, USA); casp-7 from Cell Signaling Technology (Beverly, MA, USA); Bcl- $\mathrm{X}_{L}$ from BD Transduction Laboratories (Franklin Lakes, NJ, USA); Bcl-2 from Dako Diagnostics (Glostrup, Denmark); NOXA from Calbiochem (San Diego, CA, USA); and tubulin (clone AC-74) from Sigma Chemical (St Louis, MO, USA). Secondary antibodies were either anti-mouse or anti-rabbit from GE Healthcare. Image $\mathrm{J}$ was used to quantify changes in protein levels induced by bortezomib, considering untreated controls as reference for basal expression. Caspase processing was analyzed by immunoblotting with specific antibodies. Changes in the inactive/cleaved forms of specific caspases were quantified using Image $\mathrm{J}$ software and plotted as a function of time.

Cell death assays/Cyt $c$ visualization. The percentage of cell death at the indicated times and drug concentrations was estimated by standard trypan blue exclusion assays. Briefly, floating and adherent cells were pooled, stained with a $0.4 \%$ trypan blue solution (Gibco Laboratories, Grand Island, NY, USA) and scored under a light microscope (a minimum of 500 cells per treatment were counted). Cyt $c$ localization was visualized by immunofluorescence in cells fixed with $4 \%$ formaldehyde essentially as described previously. ${ }^{30}$ Where indicated, nuclei were stained with 4',6-diamidino-2-phenylindole (DAPI) using standard methods.

RNA interference. Lentiviral vectors used to downregulate $\mathrm{Bcl}-2, \mathrm{Bcl}-\mathrm{x}_{\mathrm{L}}, \mathrm{Mcl}-1$ and NOXA have been previously reported. ${ }^{6,30}$ In summary, the sequences used to generate short hairpin interfering RNAs were as follows. Bcl-2 (1): nt. 197-215; Bcl2 (2): nt. 500-518; Bcl-X : nt. 714-732; Mcl-1: nt. 2343-2362; and NOXA: nt. 11771195. Unspecific oligonucleotides were also designed to generate control shRNA. Viruses were generated from 293FT cells and titers were used to provide $>80 \%$ infection efficiency. The efficacy and specificity of each construct was determined by protein immunoblotting (see text). When indicated, treatment with bortezomib was initiated 3 days after infection with the corresponding shRNA-expressing viruses.

Analysis of drug response in animal models (mouse xenografts). Female athymic nude mice (Taconic Farms, Hudson, NY, USA) were kept in pathogen-free conditions and used at 8-12 weeks of age. Animal care was provided in accordance with the procedures outlined in the Guide for the Care and Use of Laboratory Animals of the University of Michigan. To analyze localized growth of melanoma cells in vivo, $0.5 \times 10^{6}$ GFP-tagged melanoma cells were injected s.c. in the rear flanks of athymic nude mice ( $n=10$ tumors per experimental 
condition). As surrogate for metastatic dissemination of melanoma cells, $1 \times 10^{6}$ GFP-expressing melanoma cells were injected i.v. into the mouse tail vein $(n=10)$. Treatment was initiated 48 or $72 \mathrm{~h}$ after the s.c. or i.v. tumor implantations, respectively. Animals were weighed every 2 days to ensure maintenance of total weight within $80 \%$ of control populations. Bortezomib was administered systemically by intraperitoneal injection $(1.0-1.3 \mathrm{mg} / \mathrm{kg})$ in a rotating 2-day schedule. ${ }^{6}$ Similar results were obtained for treatments performed via i.v. administration (data not shown). (-)-Gossypol was administered orally at a daily dose of $15-20 \mathrm{mg} / \mathrm{kg}$. Imaging of tumor cells in vivo was performed with an Illumatool TLS LT-9500 fluorescence light system (Lightools Research, Encinitas, CA, USA) and the emitted fluorescence from tumor cells was captured with a Hamamatsu Orca $100 \mathrm{CCD}$ camera. Volumes of the s.c. xenografts were estimated as $V=L W^{2} / 2$, where $L$ and $W$ stand for tumor length and width, respectively. Pathological analyses of internal organs were guided by fluorescence imaging. Lungs and lymph nodes were harvested and weighed, and external metastases were counted manually and scored by number and size. Metastatic involvement was monitored independently by analysis of hematoxylin-eosin staining of paraffin sections. Mice were euthanized when control populations showed signs of discomfort or respiratory defects.

Statistical analyses. Statistical evaluation of tumor growth and metastasis in vivo was performed using the Statistical Package of the Social Sciences (SPSS) version 11.5 for Windows. Non-parametric Kruskal-Wallis $H$-test was used for $\mathrm{X}$-group comparisons and Mann-Whitney U-test for two-group comparisons. Two-tailed $P$-values smaller than 0.05 were considered statistically significant.

Acknowledgements. We thank Wen-Hua Tang and Ryan Stork for technical assistance, Jianyong Chen for the purification of (-)-gossypol, and Joshua Bauer and Thomas Carey for help with the generation and validation of the shRNAs for $\mathrm{Bcl}-2, \mathrm{Mcl}-1$ and $\mathrm{BCl}-\mathrm{x}_{\mathrm{L}}$. We also thank José Esteban and Gabriel Núñez for critical reading of this paper. This work was supported by Career Development Awards from the Dermatology Foundation and the Elsa Pardee Foundation (MSS), and Grants NIH R01 CA107237 (MSS), U19CA113317 (SW) and T32 GM 008616-06A1 (KW).

1. Jemal A, Siegel R, Ward E, Murray T, Xu J, Smigal $C$ et al. Cancer statistics, 2006. $C A$ Cancer J Clin 2006; 56: 106-130.

2. Soengas MS, Lowe SW. Apoptosis and melanoma chemoresistance. Oncogene 2003; 22 3138-3151.

3. Chin L, Garraway LA, Fisher DE. Malignant melanoma: genetics and therapeutics in the genomic era. Genes Dev 2006; 20: 2149-2182.

4. Amiri KI, Horton LW, LaFleur BJ, Sosman JA, Richmond A. Augmenting chemosensitivity of malignant melanoma tumors via proteasome inhibition: implication for bortezomib (VELCADE, PS-341) as a therapeutic agent for malignant melanoma. Cancer Res 2004; 64: 4912-4918.

5. Fernandez Y, Miller TP, Denoyelle C, Esteban JA, Tang WH, Bengston AL et al. Chemical blockage of the proteasome inhibitory function of bortezomib: impact on tumor cell death. J Biol Chem 2006; 281: 1107-1118.

6. Fernandez Y, Verhaegen M, Miller TP, Rush JL, Steiner P, Opipari Jr AW et al. Differential regulation of noxa in normal melanocytes and melanoma cells by proteasome inhibition: therapeutic implications. Cancer Res 2005; 65: 6294-6304.

7. Qin JZ, Xin H, Sitailo LA, Denning MF, Nickoloff BJ. Enhanced killing of melanoma cells by simultaneously targeting Mcl-1 and NOXA. Cancer Res 2006; 66: 9636-9645.

8. Qin JZ, Ziffra J, Stennett L, Bodner B, Bonish BK, Chaturvedi V et al. Proteasome inhibitors trigger NOXA-mediated apoptosis in melanoma and myeloma cells. Cancer Res 2005; 65 6282-6293.

9. Adams J. The development of proteasome inhibitors as anticancer drugs. Cancer Cell 2004; 5: 417-421.

10. Fribley AM, Evenchik B, Zeng Q, Park BK, Guan JY, Zhang H et al. Proteasome inhibitor PS-341 induces apoptosis in cisplatin-resistant squamous cell carcinoma cells by induction of Noxa. J Biol Chem 2006; 281: 31440-31447.

11. Perez-Galan $P$, Roue G, Villamor N, Montserrat E, Campo E, Colomer D. The proteasome inhibitor bortezomib induces apoptosis in mantle-cell lymphoma through generation of ROS and Noxa activation independent of p53 status. Blood 2006; 107: 257-264.

12. Naik E, Michalak EM, Villunger A, Adams JM, Strasser A. Ultraviolet radiation triggers apoptosis of fibroblasts and skin keratinocytes mainly via the BH3-only protein Noxa. J Cell Biol 2007; 176: 415-424.
13. Chen L, Willis SN, Wei A, Smith BJ, Fletcher Jl, Hinds MG et al. Differential targeting of prosurvival bcl-2 proteins by their BH3-only ligands allows complementary apoptotic function. Mol Cell 2005; 17: 393-403.

14. Kuwana T, Bouchier-Hayes L, Chipuk JE, Bonzon C, Sullivan BA, Green DR et al. BH3 domains of $\mathrm{BH} 3$-only proteins differentially regulate Bax-mediated mitochondrial membrane permeabilization both directly and indirectly. Mol Cell 2005; 17: 525-535.

15. Markovic SN, Geyer SM, Dawkins F, Sharfman W, Albertini M, Maples W et al. A phase II study of bortezomib in the treatment of metastatic malignant melanoma. Cancer 2005; 103 2584-2589.

16. Mitsiades N, Mitsiades CS, Poulaki V, Chauhan D, Fanourakis G, Gu X et al. Molecular sequelae of proteasome inhibition in human multiple myeloma cells. Proc Natl Acad Sc USA 2002; 99: 14374-14379.

17. Herrant M, Jacquel A, Marchetti S, Belhacene N, Colosetti P, Luciano F et al. Cleavage of $\mathrm{Mcl}-1$ by caspases impaired its ability to counteract Bim-induced apoptosis. Oncogene 2004; 23: 7863-7873.

18. Letai A. Pharmacological manipulation of Bcl-2 family members to control cell death. J Clin Invest 2005; 115: 2648-2655.

19. Wang S, Yang D, Lippman ME. Targeting Bcl-2 and Bcl-XL with nonpeptidic small-molecule antagonists. Semin Oncol 2003; 30: 133-142.

20. Zhai D, Jin C, Satterthwait AC, Reed JC. Comparison of chemical inhibitors of antiapoptotic Bcl-2-family proteins. Cell Death Differ 2006; 13: 1419-1421.

21. Oltersdorf T, Elmore SW, Shoemaker AR, Armstrong RC, Augeri DJ, Belli BA et al. An inhibitor of Bcl-2 family proteins induces regression of solid tumours. Nature 2005; 435 677-681.

22. Chauhan D, Velankar M, Brahmandam M, Hideshima T, Podar K, Richardson $\mathrm{P}$ et al. A novel $\mathrm{Bcl}-2 / \mathrm{Bcl}-\mathrm{X}(\mathrm{L}) / \mathrm{Bcl}-\mathrm{w}$ inhibitor $\mathrm{ABT}-737$ as therapy in multiple myeloma. Oncogene 2007; 26: 2374-2380

23. Dodou K, Anderson RJ, Small DA, Groundwater PW. Investigations on gossypol: past and present developments. Expert Opin Investig Drugs 2005; 14: 1419-1434.

24. Wang G, Nikolovska-Coleska Z, Yang CY, Wang R, Tang G, Guo J et al. Structure-based design of potent small-molecule inhibitors of anti-apoptotic Bcl-2 proteins. J Med Chem 2006; 49: 6139-6142.

25. Shelley MD, Hartley L, Fish RG, Groundwater P, Morgan JJ, Mort D et al. Stereo-specific cytotoxic effects of gossypol enantiomers and gossypolone in tumour cell lines. Cancer Lett 1999; 135: 171-180

26. Blackstaffe L, Shelley MD, Fish RG. Cytotoxicity of gossypol enantiomers and its quinone metabolite gossypolone in melanoma cell lines. Melanoma Res 1997; 7: 364-372.

27. Tuszynski GP, Cossu G. Differential cytotoxic effect of gossypol on human melanoma, colon carcinoma, and other tissue culture cell lines. Cancer Res 1984; 44: 768-771.

28. Lei X, Chen Y, Du G, Yu W, Wang X, Qu H et al. Gossypol induces Bax/Bak-independent activation of apoptosis and cytochrome $c$ release via a conformational change in $\mathrm{Bcl}-2$. FASEB J 2006

29. van Delft MF, Wei AH, Mason KD, Vandenberg CJ, Chen L, Czabotar PE et al. The $\mathrm{BH} 3$ mimetic $\mathrm{ABT}-737$ targets selective $\mathrm{Bcl}-2$ proteins and efficiently induces apoptosis via Bak/Bax if Mcl-1 is neutralized. Cancer Cell 2006; 10: 389-399.

30. Verhaegen M, Bauer JA, Martin de la Vega C, Wang T, Wolter KG, Brenner JC et al. A novel $\mathrm{BH} 3$ mimetic reveals a MAPK-dependent mechanism of melanoma cell survival controlled by p53 and reactive oxygen species. Cancer Res 2006; 66: 11348-11359.

31. Yamamura K, Kamada $S$, Ito $S$, Nakagawa $K$, Ichihashi $M$, Tsujimoto $Y$. Accelerated disappearance of melanocytes in bcl-2-deficient mice. Cancer Res 1996; 56: $3546-3550$

32. Olie RA, Hafner C, Kuttel R, Sigrist B, Willers J, Dummer R et al. Bcl-2 and bcl-xL antisense oligonucleotides induce apoptosis in melanoma cells of different clinical stages. J Invest Dermatol 2002; 118: 505-512.

33. Strasser A, O'Connor L, Dixit VM. Apoptosis signaling. Annu Rev Biochem 2000; 69 217-245.

34. Green DR. At the gates of death. Cancer Cell 2006; 9: 328-330.

35. Youle RJ. Cell biology: cellular demolition and the rules of engagement. Science 2007; 315: 776-777.

36. Schwartz R, Davidson T. Pharmacology, pharmacokinetics, and practical applications of bortezomib. Oncology (Huntingt) 2004; 18: 14-21.

37. Willis SN, Fletcher JI, Kaufmann T, van Delft MF, Chen L, Czabotar PE et al. Apoptosis initiated when $\mathrm{BH} 3$ ligands engage multiple $\mathrm{Bcl}-2$ homologs, not bax or bak. Science 2007 315: 856-859.

38. Certo M, Del Gaizo Moore V, Nishino M, Wei G, Korsmeyer S, Armstrong SA et al Mitochondria primed by death signals determine cellular addiction to antiapoptotic BCL-2 family members. Cancer Cell 2006; 9: 351-365.

39. Kim H, Rafiuddin-Shah M, Tu HC, Jeffers JR, Zambetti GP, Hsieh JJ et al. Hierarchical regulation of mitochondrion-dependent apoptosis by BCL-2 subfamilies. Nat Cell Biol 2006; 8: $1348-1358$.

40. Mitsiades N, Mitsiades CS, Poulaki V, Chauhan D, Fanourakis G, Gu X et al. Molecular sequelae of proteasome inhibition in human multiple myeloma cells. Proc Natl Acad Sci USA 2002; 99: 14374-14379. 